\title{
In-Depth Experimental Analysis of Influence of Electroplated Gold Thickness on Thermal and Electro-Optical Properties of mid-IR AlInAs/InGaAs/InP Quantum Cascade Lasers
}

\author{
Dorota Pierścińska *(D), Kamil Pierściński, Grzegorz Sobczak (D), Katarzyna Krajewska (D), Krzysztof Chmielewski (D), \\ Aleksandr Kuźmicz, Krzysztof Piskorski and Piotr Gutowski
}

Citation: Pierścińska, D.; Pierściński, K.; Sobczak, G.; Krajewska, K.; Chmielewski, K.; Kuźmicz, A.; Piskorski, K.; Gutowski, P. In-Depth Experimental Analysis of Influence of Electroplated Gold Thickness on Thermal and Electro-Optical Properties of mid-IR AlInAs / InGaAs/InP Quantum Cascade Lasers. Materials 2021, 14, 7352. https://doi.org/10.3390/ma14237352

Academic Editor: Aivaras Kareiva

Received: 3 November 2021

Accepted: 27 November 2021

Published: 30 November 2021

Publisher's Note: MDPI stays neutral with regard to jurisdictional claims in published maps and institutional affiliations.

Copyright: (c) 2021 by the authors. Licensee MDPI, Basel, Switzerland. This article is an open access article distributed under the terms and conditions of the Creative Commons Attribution (CC BY) license (https:/ / creativecommons.org/licenses/by/ $4.0 /)$.
Łukasiewicz Instytut Mikroelektroniki i Fotoniki (Ł-IMiF), 02-668 Warsaw, Poland; kamil.pierscinski@imif.lukasiewicz.gov.pl (K.P.); grzegorz.sobczak@imif.lukasiewicz.gov.pl (G.S.); katarzyna.krajewska@imif.lukasiewicz.gov.pl (K.K.); krzysztof.chmielewski@imif.lukasiewicz.gov.pl (K.C.); aleksandr.kuzmicz@imif.lukasiewicz.gov.pl (A.K.); krzysztof.piskorski@imif.lukasiewicz.gov.pl (K.P.); piotr.gutowski@imif.lukasiewicz.gov.pl (P.G.)

* Correspondence: dorota.pierscinska@imif.lukasiewicz.gov.pl

\begin{abstract}
In this paper, we have examined the influence of electroplated gold thickness on the thermal and electro-optical properties of mid-IR AlInAs/InGaAs, InP QCLs. The experimental results show a significant reduction of the temperature of QCL active region (AR) with increasing gold layer thickness. For QCLs with $5.0 \mu \mathrm{m}$ gold thickness, we observed a $50 \%$ reduction of the active region temperature. An improvement of key electro-optical parameters, that is, threshold current density and maximum emitted power for structures with thick gold, was observed. The results of micro-Raman characterization show that the electroplated gold layer introduces only moderate compressive strain in top InP cladding, which is well below the critical value for the creation of misfit dislocations.
\end{abstract}

Keywords: quantum cascade lasers; thermoreflectance; Raman spectroscopy; gold electroplating

\section{Introduction}

Quantum cascade lasers (QCLs) have become the laser sources of choice in the midinfrared. Owing to their range of available wavelengths [1], wide tunability [2], single mode emission [3] and high optical power at room temperature [4], quantum cascade lasers can provide efficient and versatile single mode light sources for molecular spectroscopy of trace gases and air pollutants. QCLs are also a promising source for mid-IR free-space communications at multi-gigabit transmission rates $[5,6]$. The specific characteristic of QCLs is that they operate at a relatively high current and voltage. Due to relatively low electrical energy conversion efficiency, most of the supplied electric power is converted to heat. This process is especially important because, even for the best performing devices, the wall-plug efficiency of mid-IR QCLs operating at room temperature is still limited to about $20 \%$ under pulse-mode operation [7]. The excess Joule heating localized mostly inside the active region [8] raises the device's internal temperature [9], resulting in a decrease of output power and device degradation [10]. The heat dissipation plays a critical role in the device performance of mid-IR QCLs. Among the methods used to reduce the laser overheating are the optimization of the laser active region and waveguide design, the processing technology, mounting and device packaging [11-15].

In this paper, we analyze the influence of electroplated gold layer thickness on the performance of ridge waveguide (RW) AlInAs/InGaAs/InP QCLs. In the case of investigated devices (RW QCLs mounted epi-side up), the thick gold layer has a significant effect on the thermal behavior of the laser as the thermal conductivity of gold is high ( $315 \mathrm{~W} / \mathrm{mK}$ [16]) and it is located close to the heat source (active area of the laser). The AlInAs/InGaAs/InP QCLs with different thicknesses of gold layer have been fabricated and characterized 
thermally, showing a significant reduction of temperatures in AR (active region) and an improvement of key electro-optical parameters for structures with $5.0 \mu \mathrm{m}$ gold layer thickness. We have examined key electro-optical, thermal and spectral parameters of the investigated devices. The processing-induced strain in devices with different gold layer thicknesses has been analyzed by micro-Raman spectroscopy. The results clearly confirm that a thick electroplated gold layer on top of the contact layer can be as efficient in heat extraction from the active region as a more complicated buried heterostructure approach.

\section{Materials}

The examined QCLs are based on the strain-compensated $\operatorname{In}_{0.67} \mathrm{Ga}_{0.33} \mathrm{As} / \mathrm{In}_{0.36} \mathrm{Al}_{0.64} \mathrm{As}$ active region, designed for emission at the wavelength around $4.5 \mu \mathrm{m}$. The active region design is based on four quantum wells and uses a two phonon resonance depopulation scheme $[17,18]$. The basic segment consists of eleven well-barrier pairs and is repeated 50 times. The layer sequence, starting from the injection barrier, is as follows: $3.8,1.2,1.3,4.3,1.3,3.8,1.4,3.6,2.2,2.8,1.7,2.5,1.8,2.2,1.9,2.1,2.1,2.0,2.1$, $1.8,2.7,1.8 \mathrm{~nm}$ [19]. The $\mathrm{In}_{0 \cdot 36} \mathrm{Al}_{0 \cdot 64}$ As layers are denoted in blue bold font, and the $\mathrm{In}_{0.67} \mathrm{Ga}_{0.33} \mathrm{As}$ layers are denoted in normal font. The underlined layers $\left(\operatorname{In}_{0.36} \mathrm{Al}_{0.64} \mathrm{As}\right)$ are doped with silicon to a concentration of $4.0 \times 10^{17} \mathrm{~cm}^{-3}$. The active region was sandwiched between two $500 \mathrm{~nm}$ thick lattice matched $\mathrm{In}_{0.53} \mathrm{Ga}_{0.47} \mathrm{As}$ layers, which were n-doped to $4.0 \times 10^{16} \mathrm{~cm}^{-3}$. These layers were placed in order to increase the confinement factor of the waveguide. The structure was grown by solid-source Molecular Beam Epitaxy (MBE) on a Riber Compact 21T reactor, on a low doped $\operatorname{InP}\left(2.0 \times 10^{17} \mathrm{~cm}^{-3}\right)$ substrate, serving as the lower waveguide. The upper waveguide was formed by $1.5 \mu \mathrm{m}$ thick InP $\left(\mathrm{n}=3.0 \times 10^{16} \mathrm{~cm}^{-3}\right)$ followed by $1.5 \mu \mathrm{m}$ thick $\operatorname{InP}\left(\mathrm{n}=1.0 \times 10^{17} \mathrm{~cm}^{-3}\right)$. The whole structure was capped with a heavily doped $\left(2.0 \times 10^{18} \mathrm{~cm}^{-3}\right), 500 \mathrm{~nm}$ thick $\operatorname{In}_{0.53} \mathrm{Ga}_{0.47} \mathrm{As}$ contact layer. The upper waveguide and contact layer were grown by MOVPE. Epitaxial overgrowth was performed using AIXTRON $3 \times 2$ " CCS MOVPE system [20].

Investigated QCLs were fabricated in RW geometry using standard processing technology, that is, a wet etching of mesa and $\mathrm{Si}_{3} \mathrm{~N}_{4}$ layer deposition for electrical insulation [21] For the current injection, $15 \mu \mathrm{m}$ wide contact windows were opened through the insulator layer using RIE-ICP plasma etching. The following types of contacts were used: $\mathrm{Ti} / \mathrm{Pt} / \mathrm{Au}$ ohmic contacts for low resistivity at the epi-side and $\mathrm{AuGe} / \mathrm{Ni} / \mathrm{Au}$ at the substrate side of the laser structure. In the next step, the contacts undergo thickening by electroplating. The devices with electroplated Au-metallization thicknesses of $1.5 \mu \mathrm{m}, 3.5 \mu \mathrm{m}$ and $5.0 \mu \mathrm{m}$ were prepared to verify the influence of the electroplated gold thickness on the performance of the devices. Thicker gold layers were also deposited; however, above $5 \mu \mathrm{m}$ the resulting quality of the gold layer degraded visually, indicating that a further increase of thickness would require additional development of the deposition process. The individual cleaved lasers, $2 \mathrm{~mm}$ long, were soldered epi-side up to Au-plated AlN submount, and then to copper mounts. Figure 1 shows optical microscope images of the ridge and top gold layer of exemplary devices with different gold thicknesses.
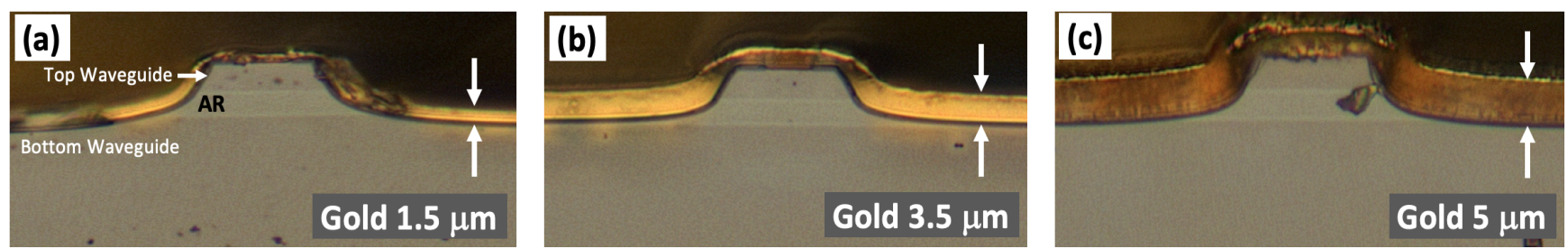

Figure 1. Optical microscope images of investigated RW AlInAs/InGaAs/InP QCLs with different electroplated gold thickness: (a) $1.5 \mu \mathrm{m}$, (b) $3.5 \mu \mathrm{m}$ and (c) $5.0 \mu \mathrm{m}$. 


\section{Results}

The basic electro-optical and thermal characterization of devices with different electroplated gold layer thicknesses was performed. Additionally, micro-Raman spectroscopy was used in order to analyze strain introduced by a thick gold layer. All studied lasers were fabricated from the same epi-wafer in one processing run.

\subsection{Electro-Optical Characterization}

Analysis of the impact of Au metallization thickness on QCLs parameters and the effectivity of heat dissipation was performed. First, the light-current-voltage (L-I-V) characteristics were measured for devices fabricated from the same epitaxial heterostructure, differing only in the gold layer thicknesses: $1.5 \mu \mathrm{m}, 3.5 \mu \mathrm{m}$ and $5.0 \mu \mathrm{m}$. Figure 2 presents L-I-V characteristics registered in pulsed mode at room temperature. The lasers were soldered epi-side up to an Au-plated AlN submount, and then to copper mounts. Lasers with uncoated facets were investigated. We used a typical set-up for QCL light-current-voltage characteristics measurement. The output power was measured using a TE (thermoelectric) cooled MCT (Mercury Cadmium Telluride) detector placed in front of the laser facet with anti-reflection-coated optics to improve light collection efficiency.

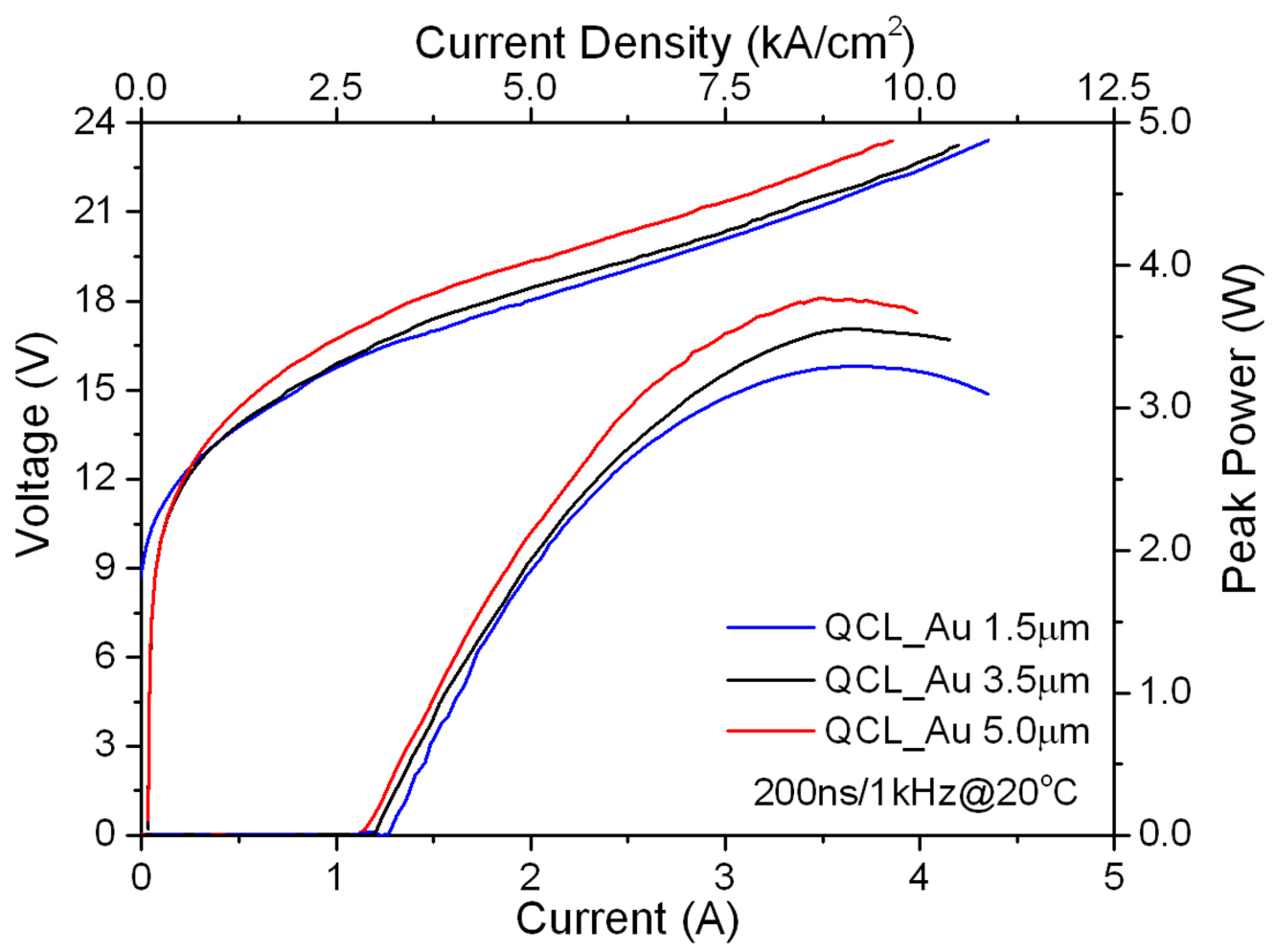

Figure 2. Room-temperature L-I-V characteristics for AlInAs/InGaAs/InP QCLs with different electroplated gold thickness.

The threshold current density decreases from $3.20 \mathrm{kAcm}^{-2}$ for the laser with $1.5 \mu \mathrm{m}$ gold layer thickness to $2.75 \mathrm{kAcm}^{-2}$ for the laser with $5.0 \mu \mathrm{m}$ gold layer thickness. At the same time, power at roll-over increases by $15 \%$. The change of threshold current can be directly related to a decrease of the active region temperature and consequently the increase of laser gain [22]. However, the comparison of electro-optical parameters of QCLs, shown in Figure 2, shows only a slight improvement of these parameters for devices with thick metallization. This is related to the power supply conditions; short pulses and low pulse repetition rates (duty cycle $\mathrm{dc}=0.02 \%$ ) for which thermal problems are not yet critical.

To clearly see the improvement of heat dissipation efficiency with the thickest $\mathrm{Au}$ metallization thickness, we have measured the changes in the maximum emitted optical power as a function of the pulse repetition frequency for a constant pulse length and 
temperature. Figure $3 \mathrm{a}, \mathrm{b}$ show how the output power decreases as the duty cycle is increased for constant pulse widths of $200 \mathrm{~ns}$ and $500 \mathrm{~ns}$, respectively. In this case, the increase of the pulse repetition frequency introduces a greater thermal load for the devices. Under such operating conditions, the improvement in heat dissipation from the active region for QCLs with thick gold metallization is more pronounced. The heat generated during the pulse is much more efficiently dissipated for the device with the thicker top gold layer. This effect results from specific dynamic thermal properties of the QCL device structure, that is, the inter-pulse heating occurs on a much longer time scale than the intra-pulse thermal dynamics [23]. In this case, we observe the typical heat accumulation effect, which becomes more pronounced, as the thermal load increases and eventually leads to the thermal quenching of lasing operation.

(a)

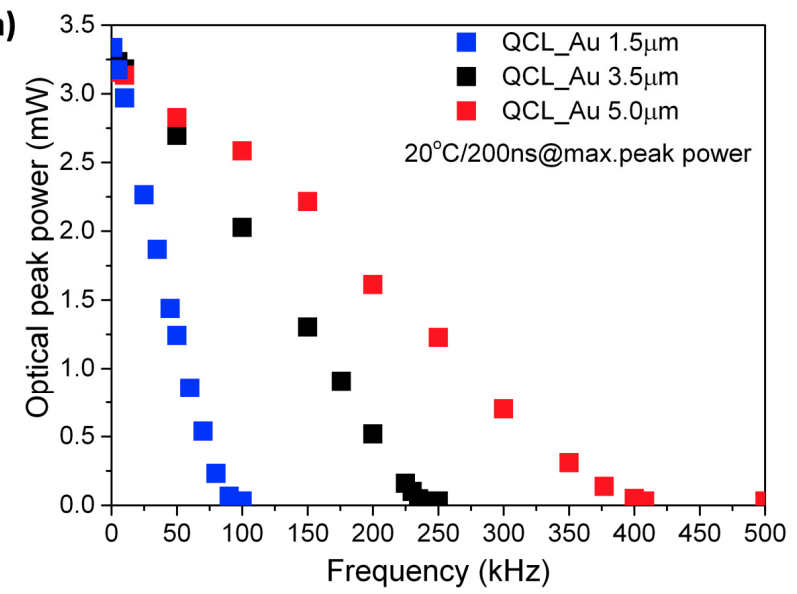

(b)

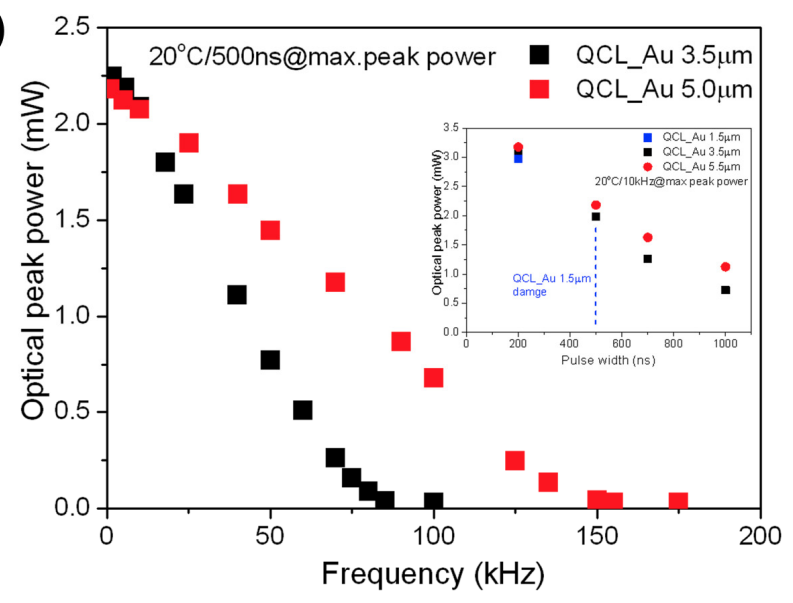

Figure 3. Optical peak power vs. frequency for investigated AlInAs/InGaAs/InP QCL with different gold thickness measured at following experimental conditions: (a) $20^{\circ} \mathrm{C} / 200 \mathrm{~ns}$ and (b) $20^{\circ} \mathrm{C} / 500 \mathrm{~ns}$. Inset in (b) shows peak power vs. pulse length at constant frequency of $10 \mathrm{kHz}$.

From Figure 3a,b, it can be seen that for a 200 ns pulse width, the device with thick gold operates at much higher pulse repetition frequencies, reaching $500 \mathrm{kHz}$, as opposed to the thin gold device, which ceases to lase at $100 \mathrm{kHz}$. At longer pulses of $500 \mathrm{~ns}$, the thin gold device was not able to operate at all, facing catastrophic damage before reaching the threshold.

The effect of gold layer thickness on the temperature of the active region was further confirmed by measuring the emission spectra of the lasers. The devices were mounted on a thermoelectric cooler held at $20^{\circ} \mathrm{C}$. The laser emission was collected from the output facet and was sent to FTIR (Fourier Transform Infrared Spectroscopy) spectrometer. Spectra were registered with $0.125 \mathrm{~cm}^{-1}$ resolution. Figure 4 shows spectral characteristics registered for QCLs operated with $200 \mathrm{~ns}$ pulses and a $5 \mathrm{kHz}$ repetition rate at a current of $1.25 \mathrm{~A}$. The data present the red shift of emission wavelength with the decrease of the gold metallization thickness, which indicates that the temperature of the active region increases for devices with thin metallization. The shift of the peak wavelength, when moving from a device with a $5.0 \mu \mathrm{m}$ gold layer to a $1.5 \mu \mathrm{m}$ device equal to $\Delta \lambda=18 \mathrm{~nm}\left(9.05 \mathrm{~cm}^{-1}\right)$, was observed. Considering an experimentally determined emission tuning rate of $0.3 \mathrm{~nm} / \mathrm{K}$, the temperature difference, between respective devices, can be estimated as $\Delta \mathrm{T}=60 \mathrm{~K}$.

\subsection{Thermal Characterization}

Direct information about the temperature of the device during pulsed operation can be obtained using the charge-coupled device (CCD)-based thermoreflectance (CCDTR) $[24,25]$, which allows for both high spatial $(0.6 \mu \mathrm{m})$ and temperature resolution (below $1 \mathrm{~K}$ ) imaging of temperature distribution on the laser facet. The optical part of the CCD-TR setup is based on the optical microscope equipped with a $100 \times$ long working distance objective. The sample is illuminated with a high intensity light emitting diode (LED) emitting 
at $630 \mathrm{~nm}$. CCD-TR data allow for the localization of main heat sources and provide information on the efficiency of heat dissipation at different driving conditions. The technique is fast and accurate and provides information otherwise difficult to obtain. Figure 5 shows temperature distribution maps on the facet of the investigated AlInAs/InGaAs/InP QCLs with different gold metallization thicknesses: $1.5 \mu \mathrm{m}, 3.5 \mu \mathrm{m}$ and $5.0 \mu \mathrm{m}$. For comparison, the maps are presented in the same temperature scale and show an area of size $65 \times 60 \mu \mathrm{m}$ of the laser ridge and the active region.

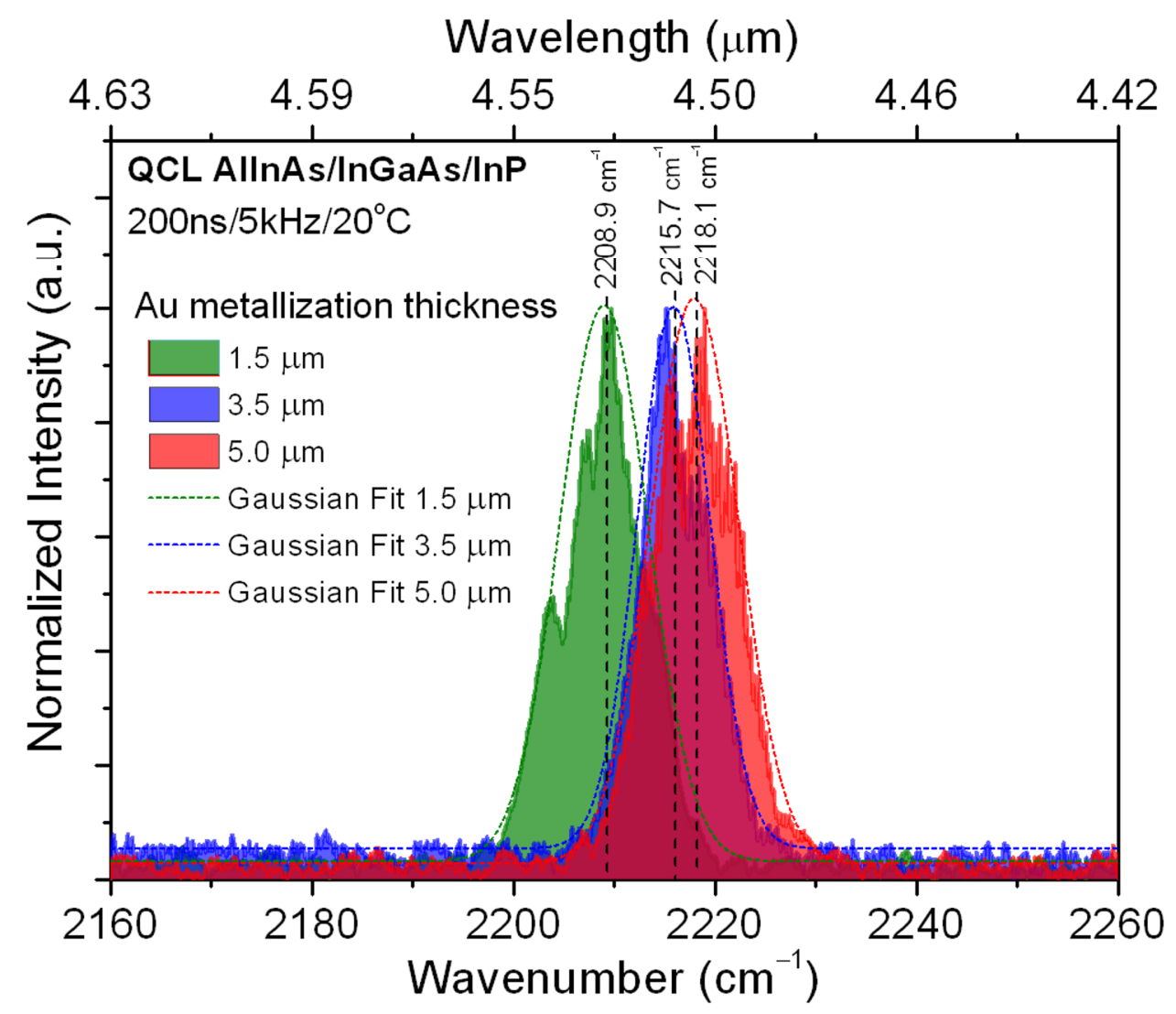

Figure 4. Emission spectra for AlInAs/InGaAs/InP QCLs with various gold metallization thickness: $5.0 \mu \mathrm{m}$ (red line), $3.5 \mu \mathrm{m}$ (blue line) and $1.5 \mu \mathrm{m}$ (green line).

For all measured lasers, the maximum temperature increase was registered in the active area of the laser. Significant differences in the heat dissipation from the active area for lasers with different gold thicknesses can be observed. For lasers with thick Au metallization, the effect of gold thickness in spreading the heat generated at the active area is clearly visible, as the maximal temperature rise is lower and the heat distribution has a different shape. For the thick gold layer, heat is dissipated laterally and extracted through the metallization. In the case of a thin gold layer, more heat is dissipated in the direction of the heatsink, which is far less efficient. Above the active region (upper InP waveguide), the effect of heat accumulation is observed. To gain further insight into heat dissipation from the active area in the lasers with different gold thicknesses, temperature line scans across the facet were taken perpendicularly to the active layer as shown in Figure 6. 


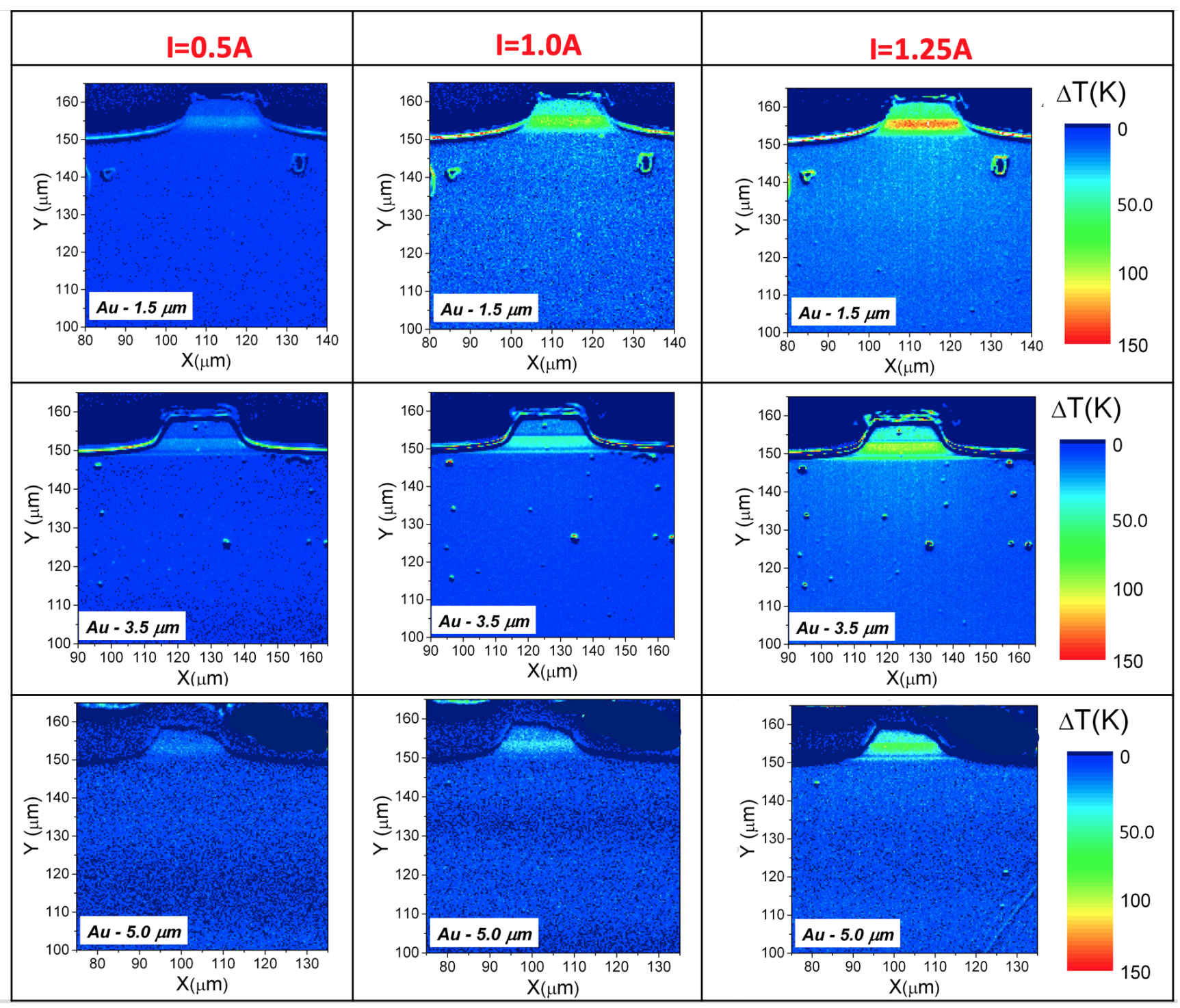

Figure 5. Thermal images of the ridge waveguide, epi-up mounted QCLs with different thickness of gold metallization, measured for pulse width of $10 \mu \mathrm{s}$, frequency $20 \mathrm{kHz}$ and driving currents I = 0.5 A, 1.0 A and 1.25 A.

Besides the general effect of lowering device temperature with an increase of electroplated gold layer thickness, one can observe improved heat extraction from the upper waveguide, which clearly demonstrates the usefulness of thick gold in device heat management.

The laser core temperature as a function of gold thickness and as a function of supply current is shown in Figure 7a,b. For a driving current of $1.25 \mathrm{~A}$, an increase of gold layer thickness from $1.5 \mu \mathrm{m}$ to $5.0 \mu \mathrm{m}$ results in a $50 \%$ reduction of active region temperature. This is roughly the same value as in the case of a buried heterostructure $(\mathrm{BH})$ mounted epi-down design, which is considered the most effective in terms of heat extraction [25]. However, considering that $\mathrm{BH}$ technology requires two-step epitaxy and complicated processing, thick electroplated gold technology seems to be a promising alternative, in particular in the case of cost-effective production technology.

\subsection{Micro-Raman Spectroscopy Characterization}

Micro-Raman spectroscopy is a powerful tool for the investigation of processinginduced strain in semiconductor devices created by soldering a laser chip to the heatsink, packaging or metallization processes. The Raman spectrum parameters, such as intensity, width and peak frequency, provide information on the crystal quality, lattice strain and 
doping concentration [26]. The micro-Raman spectroscopy allows detailed studies with a spatial resolution in the sub-micron range. The measurements were performed at room temperature using an exciting $\mathrm{Ar}^{+}$ion laser light of $488 \mathrm{~nm}$. The light beam was guided into a confocal microscope with a $100 \times$ objective (numerical aperture $=0.9$ ), providing a light spot diameter of $1 \mu \mathrm{m}$. The system was equipped with a monochromator with a focal length of $0.752 \mathrm{~m}$ and a nitrogen cooled CCD camera $(1024 \times 256$ pixels). The spectral resolution of the Raman system was $0.625 \mathrm{~cm}^{-1}$ per CCD-pixel for an $1800 \mathrm{~mm}^{-1}$ grating. The Rayleigh elastic scattering was rejected by an edge filter. The motorized stage allowed the positioning of the light spot at different points on the sample surface with $0.1 \mu \mathrm{m}$ steps in $x-y$ directions. The Raman spectra were measured in the backscattering configuration with incident light perpendicular to the sample surface. The power of light was set below $1 \mathrm{~mW}$ to avoid laser induced surface heating.

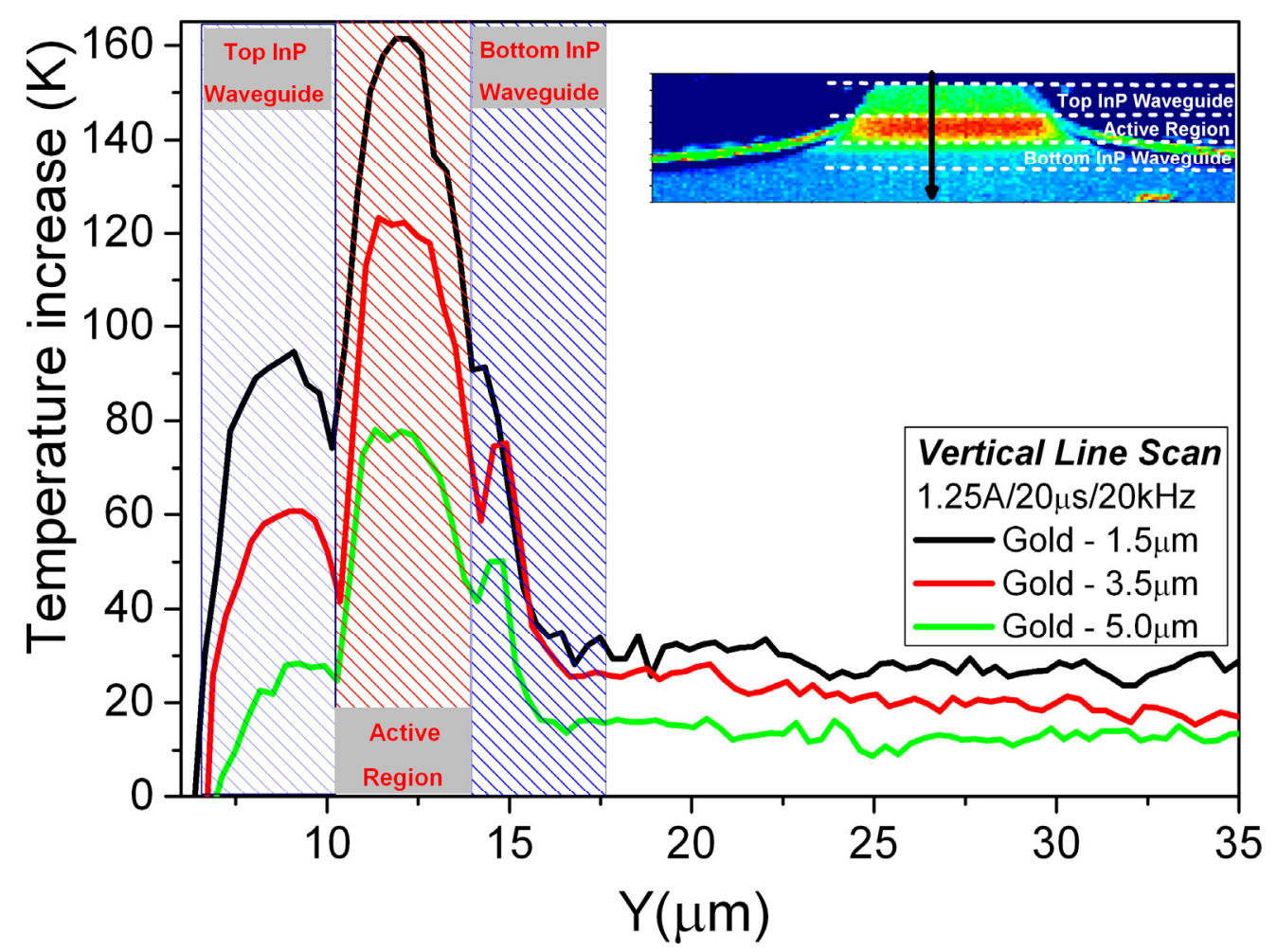

Figure 6. Vertical temperature profiles across the facet for devices with different gold thickness taken along the line as shown in the inset.

The Raman spectra were measured on three lasers with different thicknesses of the gold layer. For each laser, the InP cladding layer was measured at seven different positions, with approximately $2.5 \mu \mathrm{m}$ distance between points, along the ridge. The position in which the measurements were taken was in close proximity with contact metallization, as schematically shown in Figure 8a. The Raman spectra taken for the laser with a 1.5 micrometer thick gold layer are shown in Figure 8b. Spectra present the characteristic modes of the InP crystal. Although, for backscattering geometry on the (100) InP face, selection rules predict only the longitudinal optical LO mode at $343 \mathrm{~cm}^{-1}$. The transverse optical TO mode at $304 \mathrm{~cm}^{-1}$ is visible, which can be attributed to the failure of true backscattering geometry [26]. In the second-order optical range, the overtone bands are present at 620,653 and $683 \mathrm{~cm}^{-1}$, and can be ascribed to $2 \times \mathrm{TO}, \mathrm{LO}+\mathrm{TO}$, and $2 \times \mathrm{LO}$ modes, respectively. The dominant and sharp profiles of the InP TO peaks characterize the good crystal quality of the investigated layers. 
(a)

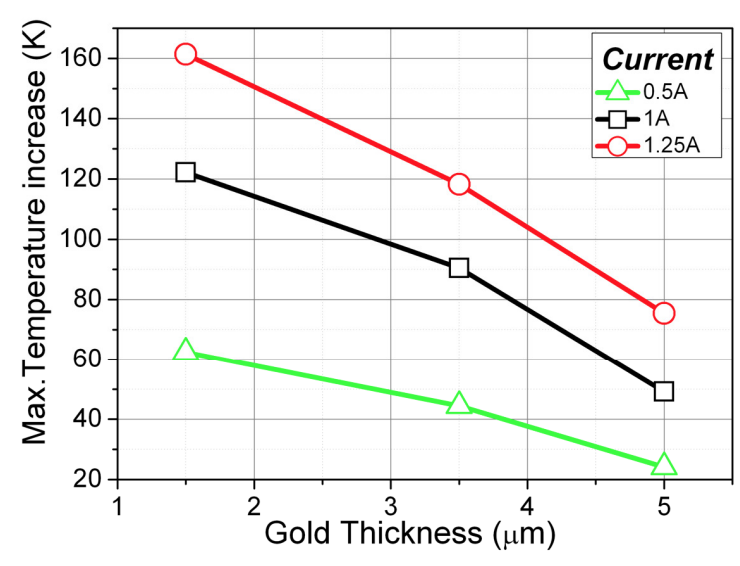

(b)

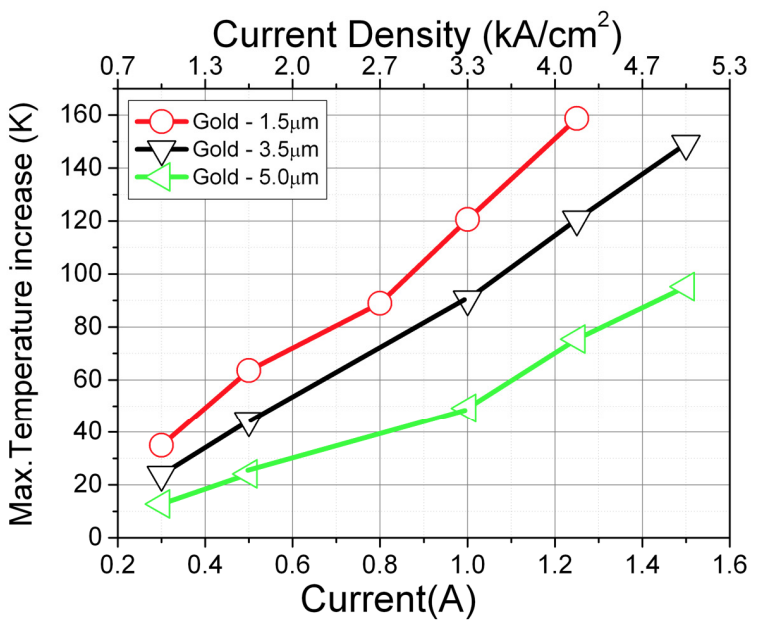

Figure 7. Laser core temperature as a function of gold thickness (a) and drive current (b).

(a)

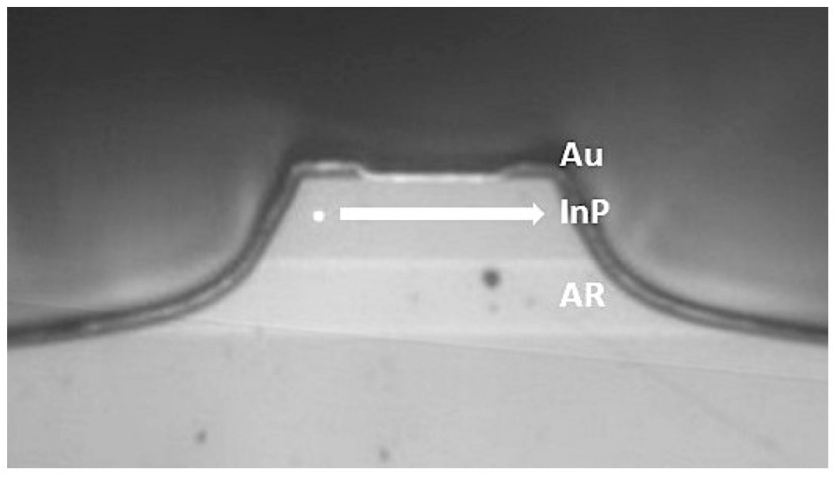

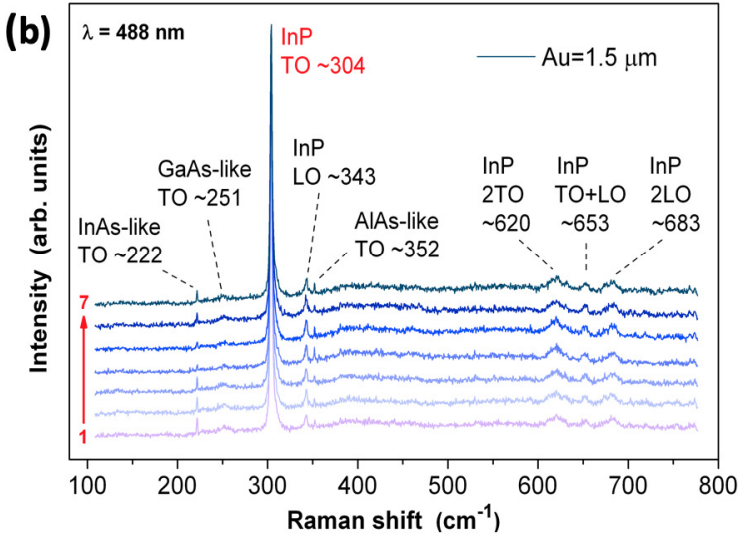

Figure 8. The image of the QCL facet showing position where Raman spectra were registered. The light spot (marked by white dot) was shifted along the InP cladding layer allowing measurements of Raman spectra at 7 different positions (a). Raman spectra registered at 7 different positions along the ridge (b).

All spectra obtained for different light spot positions (see Figure $8 b$ ) show good reproducibility; the same frequencies of the main InP TO and LO modes, as well as other peaks which prove the existence of uniform stress in the cladding layer along the gold contact. The same is true for lasers with thicker gold layers $(3.5 \mu \mathrm{m}$ and $5.0 \mu \mathrm{m})$, although peak positions are shifted to slightly higher frequencies. The spectra were normalized to the maximum intensity value of the InP TO modes for each laser. Figure 9a shows the frequencies of the InP TO modes as a function of light spot positions obtained by the fitting to Lorentzian profiles. The difference in InP TO mode frequencies exists, as shown in Figure $9 \mathrm{~b}$. For thicker gold layers, the InP TO peaks shift toward higher frequencies, which can be attributed to the mechanical stress existing in InP cladding layers.

Table 1 lists the shifts of average InP TO phonon line frequency in QCLs with different thicknesses of electroplated gold layer with respect to the InP TO phonon line of the substrate, which is treated as a reference line $\left(304.0 \mathrm{~cm}^{-1}\right.$ [26]). The values of stress in the InP cladding close to gold metallization were calculated using the following relation between Raman shift and stress [27]:

$$
\Delta \omega=-2 \times 10^{-9} \sigma
$$

Here, $\Delta \omega$ is given in units of $\mathrm{cm}^{-1}$ and $\sigma$ in Pascal (Pa). Calculated stress values are shown in Table 1. 
(a)

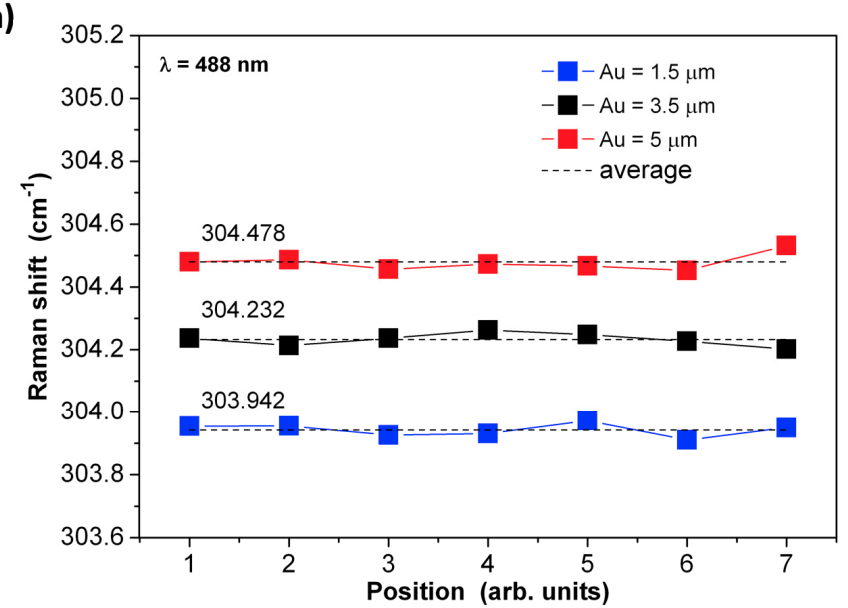

(b)

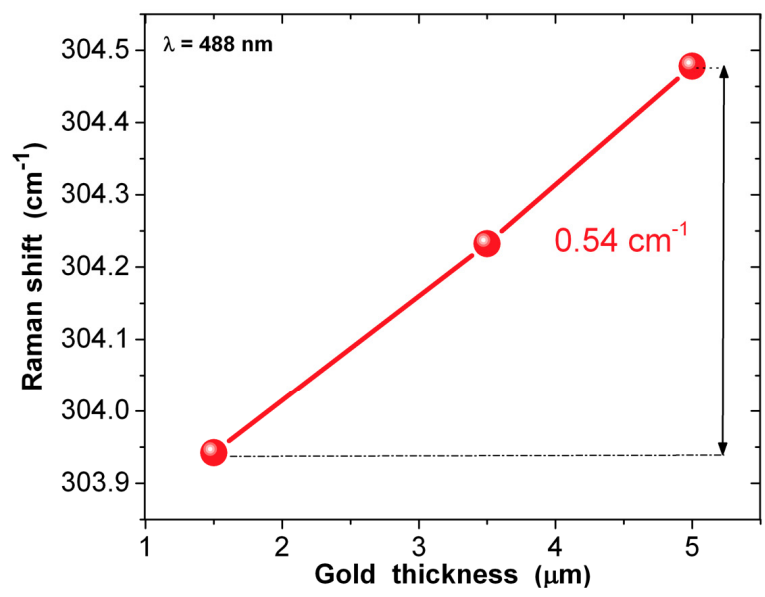

Figure 9. The frequencies of the InP TO modes in function of light spot positions obtained on the basis of Lorentzian profiles calculations. Numbers above each line indicate the average value of the InP TO peak frequency for each laser (a). Shift of InP TO frequencies in the function of gold layer thickness $(\mathbf{b})$.

Table 1. Raman shift of the TO InP phonon line and calculated stress values in reference to InP TO phonon mode of the substrate $\left(\omega=304.0 \mathrm{~cm}^{-1}\right.$ [26]). Positive $\sigma$ value means tensile stress, while negative value indicates existing of compressive stress.

\begin{tabular}{ccc}
\hline Sample & $\Delta \boldsymbol{\omega}\left[\mathbf{c m}^{-1}\right]$ & $\sigma[M P a]$ \\
\hline QCLs with 1.5 Au & -0.058 & 0.88 \\
QCLs with 3.5 Au & 0.232 & -3.5 \\
QCLs with 5.0 Au & 0.478 & -7.25 \\
\hline
\end{tabular}

The above results show that gold layers electroplated on top of laser ohmic contact, even in the case of $5.0 \mu \mathrm{m}$ thickness, introduce only moderate compressive strain in the top InP cladding. These values are well below the critical value ( 34 MPa @RT) for the generation of misfit dislocation, causing plastic relaxation in the cladding and active layers and eventually leading to device failure $[19,28,29]$.

\section{Conclusions}

In this paper, we have examined the influence of electroplated gold thickness on the thermal and electro-optical properties of mid-IR AlInAs/InGaAs, InP QCLs. The investigated QCLs were fabricated in RW geometry using standard processing technology. The devices with electroplated Au-metallization thicknesses of $1.5 \mu \mathrm{m}, 3.5 \mu \mathrm{m}$ and $5.0 \mu \mathrm{m}$ were prepared. The as-cleaved lasers, $2 \mathrm{~mm}$ long, were soldered epi-side up to Au-plated AlN submount, and then to copper mounts.

Experimental results show a significant reduction of the temperature of the QCL active region with increasing gold layer thickness. For QCLs with a $5.0 \mu \mathrm{m}$ gold thickness, we observed a $50 \%$ reduction of the active region temperature. An improvement of key electro-optical parameters, that is, a reduction of threshold current density and an increase of maximum emitted power for structures with thick gold was observed. The effect of gold layer thickness on the temperature of the active region was further confirmed by measuring the emission spectra of the lasers. The shift of the peak wavelength when moving from a device with a $5.0 \mu \mathrm{m}$ gold layer to a $1.5 \mu \mathrm{m}$ device equal to $\Delta \lambda=18 \mathrm{~nm}\left(9.05 \mathrm{~cm}^{-1}\right)$ was observed. Considering an experimentally determined emission tuning rate of $0.3 \mathrm{~nm} / \mathrm{K}$, the temperature difference between respective devices can be estimated as $\Delta \mathrm{T}=60 \mathrm{~K}$.

Direct information about the temperature of the device during pulsed operation was obtained using the CCD- thermoreflectance. Significant differences in the heat dissipation from the active area for lasers with different gold thicknesses were observed. For a thick gold layer, heat is dissipated laterally and extracted through the metallization. In the case 
of a thin gold layer, more heat is dissipated in the direction of the heatsink, which is far less efficient. Above the active region (upper InP waveguide), the effect of heat accumulation is observed.

The Raman spectra were measured with micrometer spatial resolution at different positions across the ridge in close proximity to contact metallization. All spectra obtained for a given gold layer thickness showed the same frequencies of the main InP TO and LO modes, which proves the existence of uniform stress in the cladding layer along the gold contact. With increasing gold thickness, the InP TO peaks shift toward higher frequencies. For the thickest, $5.0 \mu \mathrm{m}$ gold layer, the compressive strain introduced by metallization was estimated as $7.25 \mathrm{MPa}$, which is well below the critical value for the creation of misfit dislocations.

It has been demonstrated that a thick electroplated Au top contact in ridge waveguide geometry adds a shorter path for heat extraction and greatly improves heat removal from the active region, which makes this technology very attractive from the point of view of production technology.

Author Contributions: Conceptualization, methodology, investigation, formal analysis, visualization, funding acquisition, writing \& review \& editing of the manuscript-D.P.; investigation, methodology and visualization- K.P. (Kamil Pierściński), G.S.; investigation (fabrication of devices)-K.P. (Krzysztof Piskorski), K.K., A.K. and K.C.; Investigation (structure growth)-P.G. All authors discussed results and contributed to the formulation of conclusions. All authors have read and agreed to the published version of the manuscript.

Funding: This work was supported by National Center for Research and Development (Poland) by project TECHMATSTRATEG: SENSE no. 1/347510/15/NCBR/2018 and by project PROLAS no. MAZOWSZE/0196/19-00.

Institutional Review Board Statement: Not applicable.

Informed Consent Statement: Not applicable.

Data Availability Statement: The data that support the findings of this study are available from the corresponding author upon reasonable request.

Acknowledgments: The authors acknowledge contribution of M. Badura, B. Ściana and M. Tłaczała from Faculty of Microsystem Electronics and Photonics, Wrocław University of Science and Technology in MOVPE growth of InP waveguide layers. The authors acknowledge M. Bugajski for discussions and initial review of the manuscript.

Conflicts of Interest: The authors declare no conflict of interest.

\section{References}

1. Razeghi, M.; Lu, Q.Y.; Bandyopadhyay, N.; Zhou, W.; Heydari, D.; Bai, Y.; Slivken, S. Quantum cascade lasers: From tool to product. Opt. Express 2015, 23, 8462-8475. [CrossRef] [PubMed]

2. Zhou, W.J.; Wu, D.H.; McClintock, R.; Slivken SRazeghi, M. High performance monolithic, broadly tunable mid-infrared quantum cascade lasers. Optica 2017, 4, 1228-1231. [CrossRef]

3. Lu, Q.Y.; Bai, Y.; Bandyopadhyay, N.; Slivken, S.; Razeghi, M. 2.4 W room temperature continuous wave operation of distributed feedback quantum cascade lasers. Appl. Phys. Lett. 2011, 98, 181106. [CrossRef]

4. Wang, F.; Slivken, S.; Wu, D.H.; Razeghi, M. Room temperature quantum cascade lasers with $22 \%$ wall plug efficiency in continuous-wave operation. Opt. Express 2020, 28, 17532-17538. [CrossRef] [PubMed]

5. Pang, X.; Ozolins, O.; Zhang, L.; Schatz, R.; Udalcovs, A.; Yu, X.; Jacobsen, G.; Popov, S.; Chen, J.; Lourdudoss, S. Free-Space Communications Enabled by Quantum Cascade Lasers. Phys. Status Solidi A 2021, 218, 2000407. [CrossRef]

6. Piersciński, K.; Mikolajczyk, J.; Szabra, D.; Pierscinska, D.; Gutowski, P.; Bielecki, Z.; Bugajski, M. Analysis of InP-based QCLs designed for application in optical transmitter of free-space optics. Proc. SPIE 2017, 10437, 104370A.

7. Zhou, W.; Lu, Q.-Y.; Wu, D.-H.; Slivken, S.; Razeghi, M. High-power, continuous-wave, phase-locked quantum cascade laser arrays emitting at $8 \mu \mathrm{m}$. Opt. Express 2019, 27, 15776-15785. [CrossRef]

8. Pierścińska, D. Thermoreflectance spectroscopy-Analysis of thermal processes in semiconductor lasers. J. Phys. D: Appl. Phys. 2018, 51, 013001. [CrossRef]

9. Pierściński, K.; Pierścińska, D.; Iwińska, M.; Kosiel, K.; Szerling, A.; Karbownik, P.; Bugajski, M. Investigation of thermal properties of mid-infrared AlGaAs/GaAs quantum cascade lasers. J. Appl. Phys. 2012, 112, 043112. [CrossRef] 
10. Pierścińska, D.; Pierściński, K.; Płuska, M.; Sobczak, G.; Kuźmicz, A.; Gutowski, P.; Bugajski, M. Temperature induced degradation mechanisms of AlInAs/InGaAs/InP quantum cascade lasers. Mater. Res. Express 2018, 5, 016204. [CrossRef]

11. Pierścińska, D.; Pierściński, K.; Sobczak, G.; Gutowski, P.; Płuska, M.; Bugajski, M. Degradation of AlInAs/InGaAs/InP quantum cascade lasers due to electrode adhesion failure. Microelectron. Reliab. 2019, 99, 113-118. [CrossRef]

12. Monastyrskyi, G.; Elagin, M.; Klinkmüller, M.; Aleksandrova, A.; Kurlov, S.; Flores, Y.V.; Kischkat, J.; Semtsiv, M.P.; Masselink, W.T. Impact of heat dissipation on quantum cascade laser performance. J. Appl. Phys. 2013, 113, 134509. [CrossRef]

13. Wang, C.; Li, Z.; Liao, X.; Guan, W.; Ma, X.; Zhou, K.; Cao, J.C.; Li, H. Improved comb and dual-comb operation of terahertz quantum cascade lasers utilizing a symmetric thermal dissipation. Opt. Express 2021, 29, 29412-29422. [CrossRef] [PubMed]

14. Takagi, S.; Tanimura, H.; Kakuno, T.; Hashimoto, R.; Saito, S. Thermal Analysis for Quantum Cascade Lasers using Experiments, Simulations and Structure Function Obtained by Static Measurement. In Proceedings of the 7th International Conference on Photonics, Optics and Laser Technology, Prague, Czech Republic, 25-27 February 2019; pp. 303-307.

15. Becher, N.; Farzaneh, M.; Knipfer, B.; Sigler, C.; Kirch, J.; Boyle, C.; Botez, D.; Mawst, L.J.; Lindberg, D.F.; Earles, T. Thermal imaging of buried heterostructure quantum cascade lasers (QCLs) and QCL arrays using CCD-based thermoreflectance microscopy. J. Appl. Phys. 2019, 125, 033102. [CrossRef]

16. Figueiredo, P.; Suttinger, M.; Go, R.; Tsvid, E.; Patel, C.K.N.; Lyakh, A. Progress in high-power continuous-wave quantum cascade lasers. Appl. Opt. 2017, 56, H15-H23. [CrossRef]

17. Liu, X.; Song, K.; Davis, R.W.; Hu, M.H.; Zah, C. Design and implementation of metallization structures for epi -down bonded high-power semiconductor lasers. IEEE 2004 Electron. Compon. Technol. Conf. 2004, 1, 798.

18. Beck, M.; Hofstetter, D.; Allen, T.; Faist, J.; Oesterle, U.; Ilegems, M.; Gini, E.; Melchior, H. Continuous wave operation of a mid-infrared semiconductor laser at room temperature. Science 2002, 295, 301-305. [CrossRef]

19. Gutowski, P.; Sankowska, I.; Karbownik, P.; Pierścińska, D.; Serebrennikova, O.; Morawiec, M.; Pruszyńska-Karbownik, E.; Gołaszewska-Malec, K.; Pierściński, K.; Muszalski, J. MBE growth of strain-compensated InGaAs/InAlAs/InP quantum cascade lasers. J. Cryst. Growth 2017, 466, 22-29. [CrossRef]

20. Badura, M. MOVPE Technology of Fe-Compensated InP Layers for the Quantum Cascade Laser Applications. Int. J. Electron. Telecommun. 2020, 66, 389-394. [CrossRef]

21. Bugajski, M.; Gutowski, P.; Karbownik, P.; Kolek, A.; Hałdaś, G.; Pierściński, K.; Pierścińska, D.; Kubacka-Traczyk, J.; Sankowska, I.; Trajnerowicz, A.; et al. Mid-IR quantum cascade lasers: Device technology andnon-equilibrium Green's function modelling of electro-optical characteristics. Phys. Status Solidi 2014, 251, 1144-1157. [CrossRef]

22. Evans, C.A.; Jovanovic', V.D.; Indjin, D.; Ikonic' 'Z.; Harrison, P. Investigation of Thermal Effects in Quantum-Cascade Lasers. IEEE J. Quantum Electron. 2006, 42, 857-867. [CrossRef]

23. Wang, S.; Xu, C.; Duan, F.; Wen, B.; Rassel, S.M.S.; Tam, M.C.; Wasilewski, Z.; Wei, L.; Ban, D. Thermal dynamic imaging of mid-infrared quantum cascade lasers with high temporal-spatial resolution. J. Appl. Phys. 2020, 128, 083106. [CrossRef]

24. Pierścińska, D.; Pierściński, K.; Morawiec, M.; Karbownik, P.; Gutowski, P.; Bugajski, M. CCD thermoreflectance spectroscopy as a tool for thermal characterization of quantum cascade lasers. Semicond. Sci. Technol. 2016, 31, 115006. [CrossRef]

25. Pierścińska, D.; Pierściński, K.; Gutowski, P.; Badura, M.; Sobczak, G.; Serebrennikova, O.; Ściana, B.; Tłaczała, M.; Bugajski, M. Heat Dissipation Schemes in AlInAs/InGaAs/InP Quantum Cascade Lasers Monitored by CCD Thermoreflectance. Photonics 2017, 4, 47. [CrossRef]

26. Bedel, E.; Landa, G.; Carles, R.; Renucci, J.B.; Roquais, J.M.; Favennec, P.N. Characterization of implantation and annealing of Zn-implanted InP by Raman spectrometry. J. Appl. Phys. 1986, 60, 1980-1984. [CrossRef]

27. Kai, F. Dombrowski, Micro-Raman Investigation of Mechanical Stress in Si Device Structures and Phonons in SiGe. Ph.D. Thesis, Brandenburg University of Technology, Cottbus, Germany, 2007. Available online: https://d-nb.info/961806672/34 (accessed on 27 November 2021).

28. Spagnolo, V.; Scamarcio, G.; Marano, D.; Page, H.; Sirtori, C. Thermoelastic stress in GaAs/AlGaAs quantum cascade lasers. Appl. Phys. Lett. 2003, 82, 4639-4641. [CrossRef]

29. Li, T.; Mastro, M.; Dadgar, A. III-V Compound Semiconductor: Integration with Silicon-Based Microelectronics, 1st ed.; CRC Press: Boca Raton, FL, USA, 2019; ISBN 10: 0367383268. 